\title{
BIBECHANA
}

A Multidisciplinary Journal of Science, Technology and Mathematics ISSN 2091-0762 (Print), 2382-5340 (Online)

Journal homepage: http://nepjol.info/index.php/BIBECHANA

Publisher: Research Council of Science and Technology, Biratnagar, Nepal

\section{Polybrominated Diphenyl Ethers Perturb Axonal Growth and Actin Distribution}

\author{
Bhanu B. Neupane ${ }^{1,2,3,}$, Tao Jin ${ }^{2}$, Zhen Gu ${ }^{1}$, Frances S. Ligler ${ }^{1}$, Gufeng Wang² \\ ${ }^{1}$ Department of Biomedical Engineering, University of North Carolina at Chapel Hill and North \\ Carolina State University, Raleigh, NC 27599-7115 \\ ${ }^{2}$ Department of Chemistry, North Carolina State University, Raleigh, NC 27695-8204 \\ ${ }^{3}$ Current Affiliation: Central Department of Chemistry, Tribhuvan University, Kathmandu, Nepal \\ "Email: newbhanu@gmail.com
}

Article history: Received 6 September, 2018; Accepted 22 September, 2018

DOI: http://dx.doi.org/10.3126/bibechana.v16i0.21103

This work is licensed under the Creative Commons CC BY-NC License.

https://creativecommons.org/licenses/by-nc/4.0/

\begin{abstract}
We investigated toxicological effects of two of the most common polybrominated diphenyl ether (PBDE) flame retardants, BDE-47 and BDE-209, in model PC12 cell line under two environmentally relevant exposure conditions: long term exposure to microgram-per-liter levels of PBDEs and acute exposure to high concentrations of PBDEs. Cells treated under both long term and acute exposure conditions showed significantly perturbed cell growth and differentiation. Importantly, even when the cells were exposed to microgram-per-liter concentration of PBDEs over an extended period, both the fraction of differentiated cells and the axonal growth were affected. The calcium release assay showed that PBDEs perturbed intracellular calcium release in a concentration dependent manner, indicating that intracellular $\mathrm{Ca}^{++}$homeostasis and signaling was involved in the neurotoxicity. More interestingly, depending on PBDE concentration and exposure conditions, cytoskeleton F-actin distribution was altered.
\end{abstract}

Keywords: Actin, axons; brominated flame retardants; calcium signaling; neurons.

\section{Introduction}

Fire safety regulations require the use of flame retarding additives in a wide variety of industrial and commercial products. Brominated flame retardants are most commonly used because of their excellent fire quenching efficiency. Brominated flame retardants are available in different forms including compounds such as polybrominated diphenyl ethers (PBDEs), hexabromocyclododacane, and tetrabromobisphenol-A. Like other brominated flame retardants, PBDEs have been used in a 
broad range of products including plastics, textiles, building and filling materials, furnishings, electronics, airplanes, and motor vehicles, etc. These chemicals disseminate into the environment and degrade slowly, making them persistent organic pollutants [1]. Living beings are exposed to these chemicals via several routes including ingestion and inhalation [2-4]. Infants are more easily exposed because of more frequent hand-to-mouth and ground-contact activities, as well as breast feeding and placental transfer. The absorbed PBDEs will accumulate in blood, breast milk, and fat tissues [3-5]. Partially metabolized forms of these pollutants such as methoxylated- and hydroxylated-PBDEs are also found in human bodies [6,7].

In recent years, toxicological effects of PDBEs raised serious concerns. All forms of PBDEs, depending upon the dose and growth phase of a living species, pose mild to acute health hazards. Recently, it was found in animal models that PBDEs are responsible for neurodevelopmental disorders [8,9]. The Environmental Protection Agency (EPA) has set a safe dose of 7 micrograms per kilogram of body weight, which is "believed to be without appreciable effects" [10]. Note that although some PBDEs are banned (including BDE-47) and most of them are being phased out voluntarily in developed countries [11,12] the banned PBDEs still exist in environment, and there is a real potential for continued exposure and absorption by humans.

How PBDEs cause neurotoxicity is still unclear but may involve multiple pathways. It has been found that PBDEs disrupt endocrine systems and $\mathrm{Ca}^{++}$intracellular signaling pathways [13-15] PBDEs and the hydroxylated derivative OH-PBDEs structurally resemble thyroxin - a thyroid hormone - and may cause hypothyroidism due to direct binding. Thyroid hormone levels directly impact proper functioning of brain and other body processes [16-18]. It was also reported that several brominated flame retardants including PBDEs and their derivatives bind to estrogen, progesterone, and androgen hormone receptors and perturb their normal activity, which can lead to reproductive and developmental disorders [18]. Toxicological studies at the cellular level showed that exposure to 1-50 $\mu \mathrm{M}$ (equivalent to $\sim 1-50 \mathrm{mg} / \mathrm{L}$ ) PBDEs perturbs calcium homeostasis and signaling and can cause neurotoxicity. The neurotoxic effect of PBDE exposure can be observed using multiple end points [19-20]. For example, the PBDE exposure reduced long-term potentiation (which relates to decreased memory) and postsynaptic protein levels [21-23] in mouse hippocampus and caused abnormal motor behavior in developing zebra fish [24]. Even more disturbing was the observation that the metabolized PBDEs generated more severe health effects than parent PBDEs [22, 25].

Many of above mentioned in vivo and in vitro PBDE toxicological studies were performed in the $\mu \mathrm{M}$ (equivalent to $\sim \mathrm{mg} / \mathrm{L})$ to few $\mathrm{mM}(\sim \mathrm{g} / \mathrm{L})$ PBDE concentration range. Neuronal growth disruption under high PBDE concentrations, e.g., shorter axons, was observed, which resulted in functional deficits of neuron cells [24]. However, recent studies also showed that pre- and postnatal exposures to low concentrations of PBDEs caused significant neurobehavioral alterations in fish and rodent models $[26,27]$. The possibility that low concentrations of PBDEs interfered with axonal growth was rarely explored.

This study investigates the effect of low concentrations of PDBEs on neuronal cell growth and differentiation using cell model obtained from pheochromocytoma of the rat adrenal medulla (PC12). Using direct cell imaging, we studied the toxicity of two of the most common PBDEs: BDE-47 and BDE-209. BDE-47 was one of the most widely distributed brominated flame retardants and BDE-209 was one of the most used flame retardants in electronics.

To mimic the natural exposure conditions, low concentration of PBDEs ( $\mu \mathrm{g} / \mathrm{L}$ range) were provided throughout the cell growth and differentiation (Condition I). As a comparison to the EPA's safe limit of $7 \mu \mathrm{g} / \mathrm{kg}$ body weight, a $50 \mathrm{~kg}$ human could take in $350 \mu \mathrm{g}$ of BDE-47 per day. This amount in a 
liter of drinking water would be present at a total PBDE concentration of $350 \mu \mathrm{g} / \mathrm{L}$. Further postintake dilution as the PBDE circulated through the body would be offset to an unknown extent by intracellular accumulation over time [28]. Given the limits of predicting the in vivo concentrations, the concentrations used in Condition I were selected to be in the $\mu \mathrm{g} / \mathrm{L}$ range and lower $\mathrm{mg} / \mathrm{L}$ range.

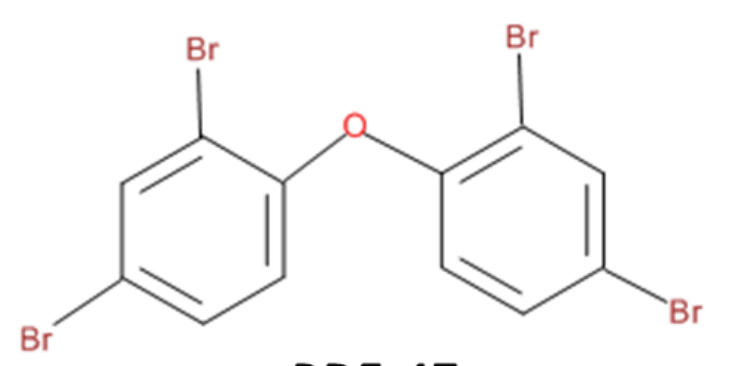

BDE-47

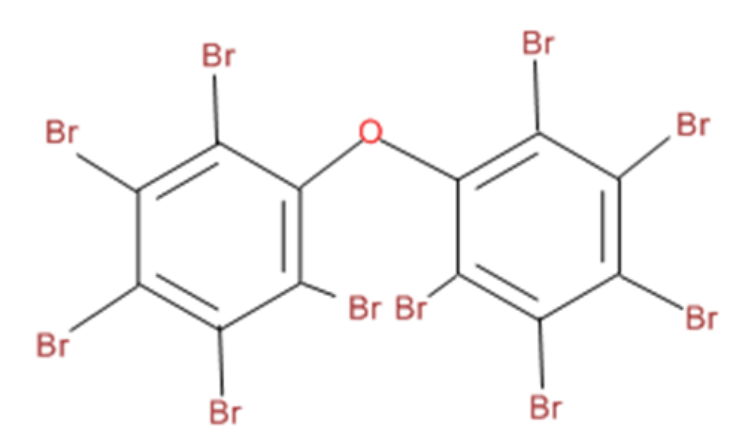

BDE-209

Scheme 1: Molecular structures of brominated flame retardants BDE-47 and BDE-209.

To provide a high-dose comparison and exposure conditions more like those generally used in the literature, we also tested the PBDE toxicity by exposing the cells to spiked PBDE concentrations in the $\mathrm{mg} / \mathrm{L}$ range for short period of time before inducing cell differentiation (Condition II). Cell morphology and the structure and localization of the cytoskeleton protein F-actin were examined. Actin plays a vital role in plasma membrane morphology, cell growth, differentiation, locomotion, and transportation [29]. In neurons, actin mediates dynamics of spine morphology, the organization of the postsynaptic density, and anchoring and trafficking of postsynaptic receptors [30-32]. Extensive changes of cell morphology are required in neuron functioning: (1) the formation of axonal and dendritic morphologies is a central feature in information processing in the central nervous system; and (2) actin filament formation at delegated sites at the cell cortex is the driving force for the induction of different protrusive structures of neurons, e.g., neurites, branches within the neuritic arbor, and dendritic spines.

We found that PC12 cell growth, differentiation and axon growth were negatively affected at PBDE concentrations as low as several to several 10s of $\mu \mathrm{g} / \mathrm{L}$. We also observed abnormal actin expression for cells exposed to low concentrations of PBDEs. F-actin distribution was perturbed by high 
concentrations of PBDEs, but not in low concentrations, indicating different pathways may be involved for axon growth inhibition at low and high exposures of PBDEs.

\section{Materials and Methods}

\subsection{Cell culture}

PC12 cells were purchased from ATCC (ATCC® CRL-1721.1 ${ }^{\mathrm{TM}}$ ). First, cells were grown in a collagen IV coated $25 \mathrm{~cm}^{2}$ cell culture flask (BDE Biosciences) in a complete base medium (ATCC, RPMI-1640 medium) supplemented with 5\% fetal bovine serum (ATCC ${ }^{\circledR} 30-2020^{\mathrm{TM}}$ )), 10\% horse serum (ATCC $\left.{ }^{\circ} 30-2040^{\mathrm{TM}}\right)$ ), and $1 \%$ penicillin streptomycin incubated under $37^{\circ} \mathrm{C}, 95 \%$ humidity, and $5 \% \mathrm{CO}_{2}$ conditions. After a week of growth in the culture flask, cells were subcultured in sterilized $2 \mathrm{~cm}^{2}$ petri dishes (Greiner Bio-One International) for 12 hours on poly-L-lysine-coated microscope coverslips (Corning, 1.5 and $22 \times 22 \mathrm{~mm}^{2}$ ). Next, cells were treated with PBDEs under two different conditions. In condition I, cells were further grown for seven days in low serum medium supplemented with $50 \mathrm{nM}$ neural growth factor (NGF 2.5S Native Mouse Protein, Life technologies) and microgram-per-liter concentration of BDE-47 $(5-2500 \mu \mathrm{g} / \mathrm{L})$ or BDE-209 $(10-5000 \mu \mathrm{g} / \mathrm{L})$. In condition II, cells were grown for 12 hours in high serum medium supplemented with a total PBDE concentration in the milligram-per-liter range: $0.5-10 \mathrm{mg} / \mathrm{L}$ BDE-47, or 1-20 mg/L BDE-209, after which the media was replaced with low serum medium supplemented with $50 \mathrm{nM}$ nerve growth factor (NGF, Life Technologies \#13257-019) to encourage differentiation over the following 6.5 days. The PBDEs used in the study were purchased from AccuStandard Inc. in solid phase and dissolved in 100\% dimethyl sulfoxide (DMSO) (BDE-47: FW 485.8 g/mol; BDE-209: FW 959.22 g/mol). The concentration of DMSO in cell culture medium was maintained less than $1 \%$. For long-term growth, culture medium containing all required supplements was changed every 48 hours.

\subsection{Cell fixation and actin staining}

Cells were washed in $1 \mathrm{X}$ phosphate buffer three times and fixed with $4 \%$ formaldehyde for 10 minutes. Cells were again washed three times with $1 \mathrm{X}$ phosphate buffer and incubated for six hours with a $10 \mu \mathrm{M}$ solution of phalloidin (a bicyclic peptide isolated from the poisonous Amanita phalloides "death cap" mushroom) conjugated with green fluorescent dye fluorescin isothiocyante (FITC) (Molecular Probes ${ }^{\circledR}$, F432). Cells were again washed with 1X phosphate buffer three times to remove unbound phalloidin-FITC.

\subsection{Optical imaging and cell viability analysis}

Optical imaging of live cells in bright field and differentiation interference contrast modes was performed by using a commercial Carl Zeiss microscope (Observer. Z1) equipped with an AxioCam CCD camera. Fluorescence imaging was done in a Nikon (Eclipse 80i) microscope equipped with an Andor iXon 897 camera. For the determination of cell viability in BFR treatment, number of adherent cells per field of view were counted and compared with untreated ones. The concentration of BFR at which $50 \%$ cell viability was observed was assigned as lethal concentration-50 (LC-50).

\subsection{Intracellular $\mathrm{Ca}^{++}$imaging}

The intracellular calcium release in live cells was measured using Abcam's Fluo-8 calcium assay kit (catalog \#ab112159) using the recommended protocol. The complete assay kit was prepared just before the experiments. Cells were grown overnight in a $2 \mathrm{~cm}^{2}$ petri disc on poly-L-lysine coated microscope coverslips in complete base medium supplemented with $0.5 \%$ fetal bovine serum. Cells were washed two times in 1X HHBS buffer (1X Hank's balanced salt solution with 20mM HEPES buffer, $\mathrm{pH}$ 7.3). The dye loading buffer was made by mixing HHBS buffer with $10 \mathrm{X}$ Pluoronic ${ }^{\circledR}$ F127 
plus (a nonionic surfactant) in 9:1 ratio. The Fluo-8 stock solution was made in $20 \mu \mathrm{L}$ of $100 \%$ DMSO. The final Fluo-8-dye loading solution was prepared by adding $20 \mu \mathrm{L}$ of Fluro-8 stock solution in $10 \mathrm{~mL}$ of dye loading buffer. Finally, $1.5-\mathrm{mL}$ of Fluro-8-dye loading solution was added to each petri disc containing cells and incubated $30 \mathrm{~min}$ in dark at $37{ }^{\circ} \mathrm{C}$. The required concentration of PBDE solution (prepared in HHBS buffer) was added to the cells and green fluorescent image were collected.

\section{Results and Discussion}

\subsection{Long term exposure to low concentration of PBDEs (Condition I)}

To mimic the long term exposure scenario, low concentrations of PBDEs were provided throughout the PC12 cell growth and differentiation conditions, i.e. Condition I. The differential interference contrast (DIC) images of PC12 cells after differentiation in the presence of 0 to $500 \mu \mathrm{g} / \mathrm{L}$ BDE-209 are shown in Figure 1A. During the differentiation period, the low serum growth medium was supplemented with nerve growth factor (NGF).(Greene, 1978) As expected, cells grown for a week without PBDE differentiated and grew long axons (Figure 1A control). The percentage of differentiated cells (as indicated by the presence of axons) was $\sim 95 \pm 5 \%$ as determined by counting cells on five cell slides.

Since the majority of dead cells were washed off the substrate when changing the cell culture medium during the growth and differentiation, the density of cells per slide also gave information on cell viability. To quantify, we counted the total number of cells in the control slides right before differentiation period as $100 \%$. The cell density dropped gradually as the concentration of PBDE increased (Figure 2A and Table 1). The number of surviving cells dropped to 50\% for cultures including $500 \mu \mathrm{g} / \mathrm{L} \mathrm{BDE}-209$. Thus, even the presence of low mass concentrations of BDE-209 during long term culture can intoxicate the PC12 cells.

For the surviving cells, the cell differentiation and axon growth were apparently perturbed. As the PBDE concentration increased, the percentage of cells with axons dropped (Figure 2B); only 50\% of cells culture with $50 \mu \mathrm{g} / \mathrm{L}$ BDE-209 displayed axons even though most of the cells were still alive. Also, the length of axons in the differentiated cells became shorter (Figure 2C). At $100 \mu \mathrm{g} / \mathrm{L}$ BDE209 , the axons were $65 \pm 15 \mu \mathrm{m}$ as compared to the length of $125 \pm 15 \mu \mathrm{m}$ measured for those from untreated PC12 cells.

A similar study for BDE-47 exposures produced the representative images shown in Figure 1B. A simple comparison of images in Figures $1 \mathrm{~A}$ and $1 \mathrm{~B}$ showed that BDE-47 was more toxic than BDE209, which is consistent with the literature [33]. The lethal concentration LC50, at which the cell viability decreased to $50 \%$, was $\sim 50 \mu \mathrm{g} / \mathrm{L} \mathrm{BDE}-47$. It is consistent that, in these low exposure studies, the fraction of differentiated cells dropped to $50 \%$ at the even lower concentration of $\sim 15 \mu \mathrm{g} / \mathrm{L} \mathrm{BDE}$ 47.

Note the concentrations in which the cells showed decreased viability or disrupted differentiation were significantly lower than the reported toxic concentrations. For example, the neuro-toxicological study of BDE-47 was reported for growing zebra fish embryos in water containing $1-20 \mu \mathrm{M}$ (equivalent to $\sim 0.5-10 \mathrm{mg} / \mathrm{L}$ ) [24]. At $\sim 1 \mu \mathrm{M}$ BDE-47, depending on the growth phase of embryos and the dorsal/ventral position of axons, $\sim 50-70 \%$ shorter axons were reported. In contrast, in the in vitro experiments, we observed that a large portion of PC12 cells did not differentiate even in $\mu \mathrm{g} / \mathrm{L}$ concentrations of PBDEs. For the surviving differentiated cells, large variations in axon lengths were observed. On average, $60 \pm 20 \mu \mathrm{m}$ long axons were found in cells treated with $\sim 50 \mu \mathrm{g} / \mathrm{L}$ BDE- 47 , which is $\sim 50 \%$ of the length of the controls $(125 \pm 15 \mu \mathrm{m})$. This study clearly showed that 
mammalian cell differentiation (fraction of cells producing axons) and axon growth (length) were disrupted at even lower concentrations of PBDEs than previously reported in the literature for studies of fish embryos.

Control

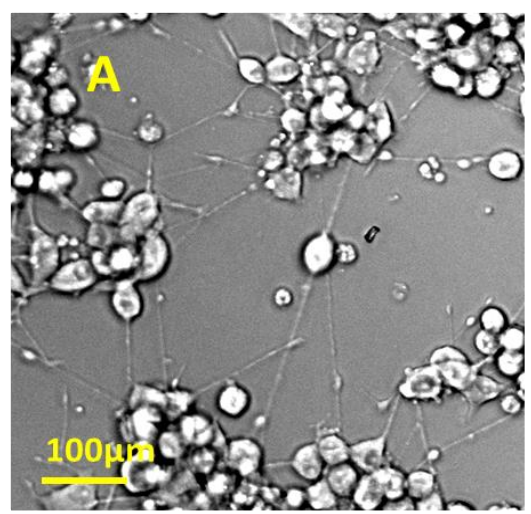

$96 \mu \mathrm{g} / \mathrm{LBDE}-209$

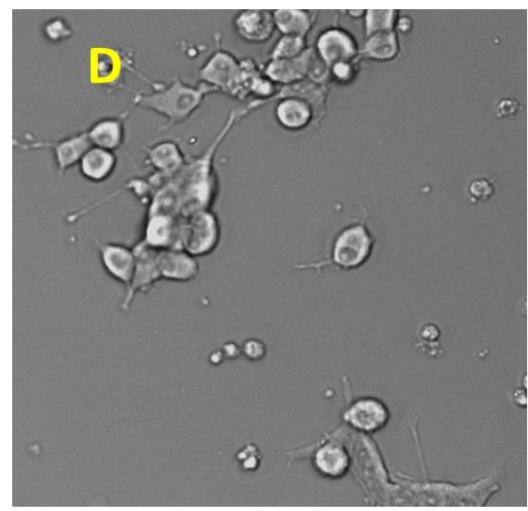

$24 \mu \mathrm{g} / \mathrm{LBDE}-47$

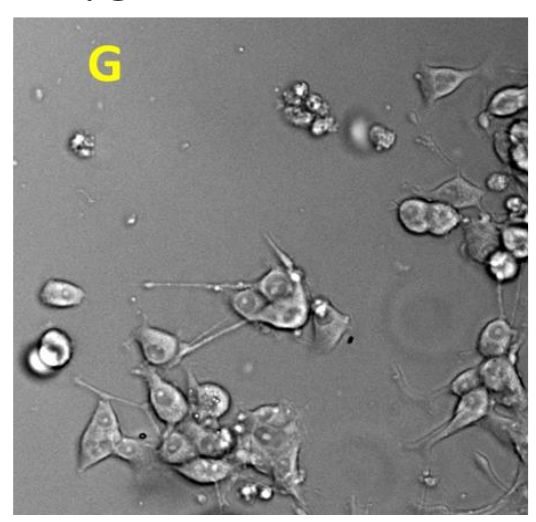

$19 \mu \mathrm{g} / \mathrm{LBDE}-209$

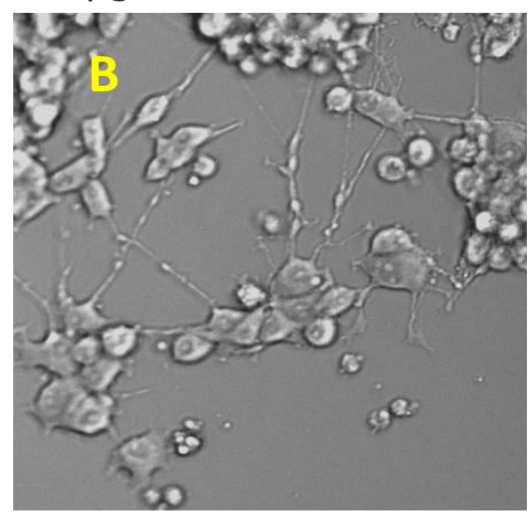

$$
480 \mu \mathrm{g} / \mathrm{L} \mathrm{BDE}-209
$$

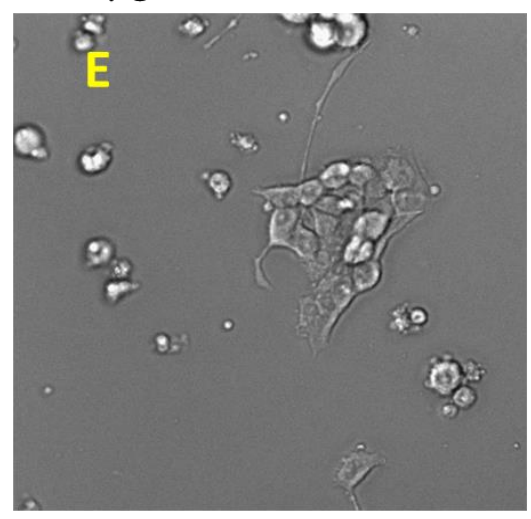

$49 \mu \mathrm{g} / \mathrm{LBDE}-47$

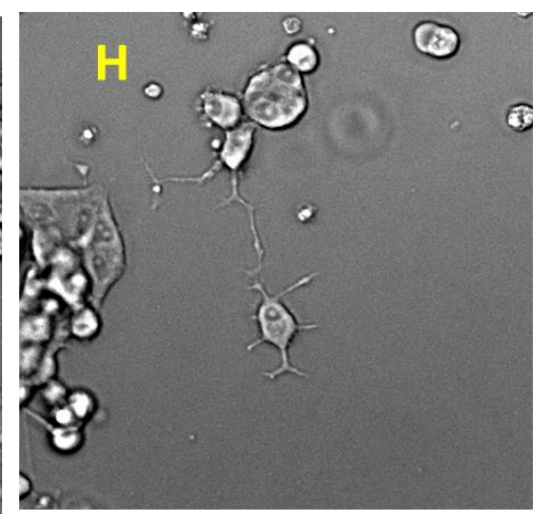

$48 \mu \mathrm{g} / \mathrm{LBDE}-209$

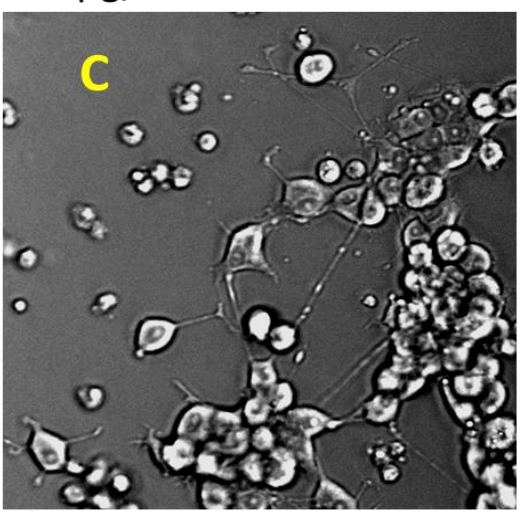

$9.7 \mu \mathrm{g} / \mathrm{L} \mathrm{BDE}-47$

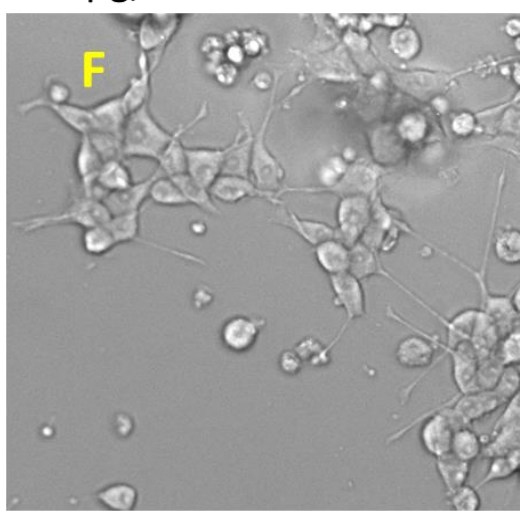

$243 \mu \mathrm{g} / \mathrm{L} \mathrm{BDE}-47$

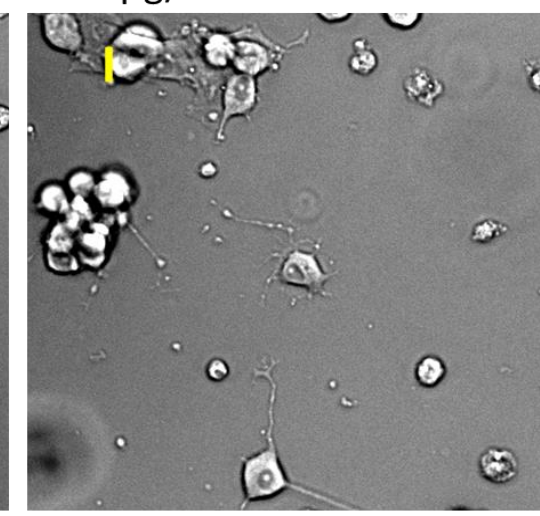

Fig. 1: DIC images of live differentiated PC12 cells treated with different concentrations of (A-E) BDE-209 and (F-I) BDE-47. Exposure condition I - long term exposure. Scale bar: $100 \mu \mathrm{m}$. 

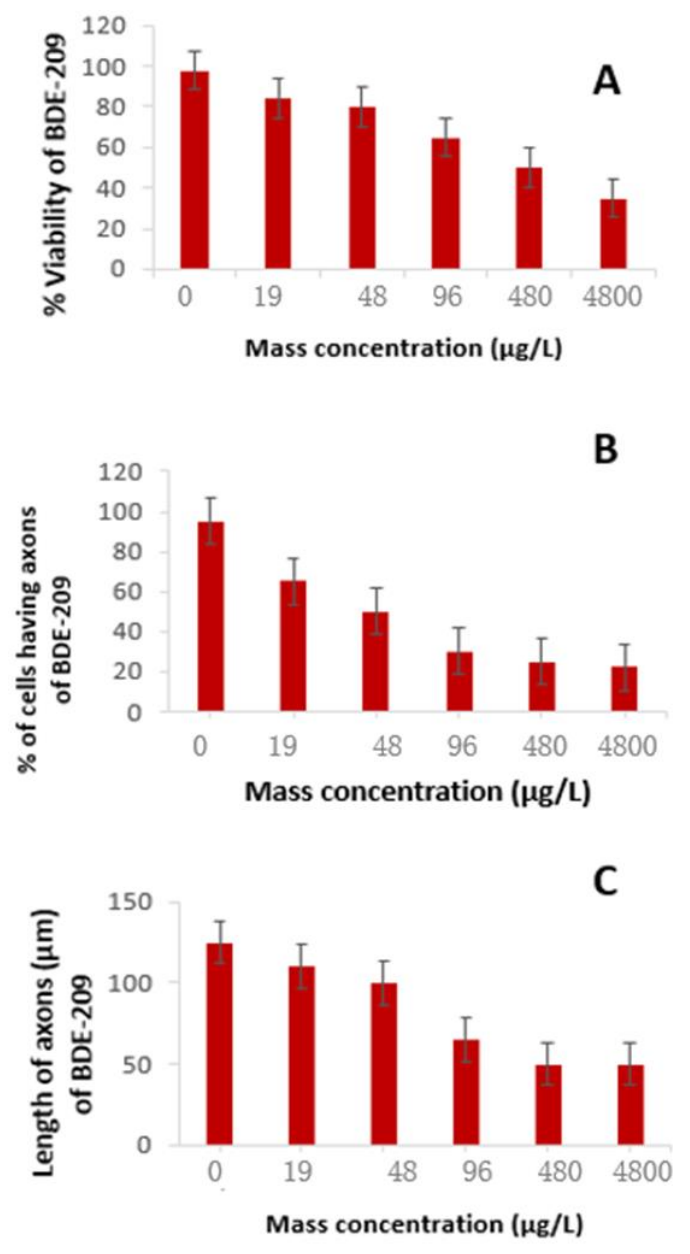
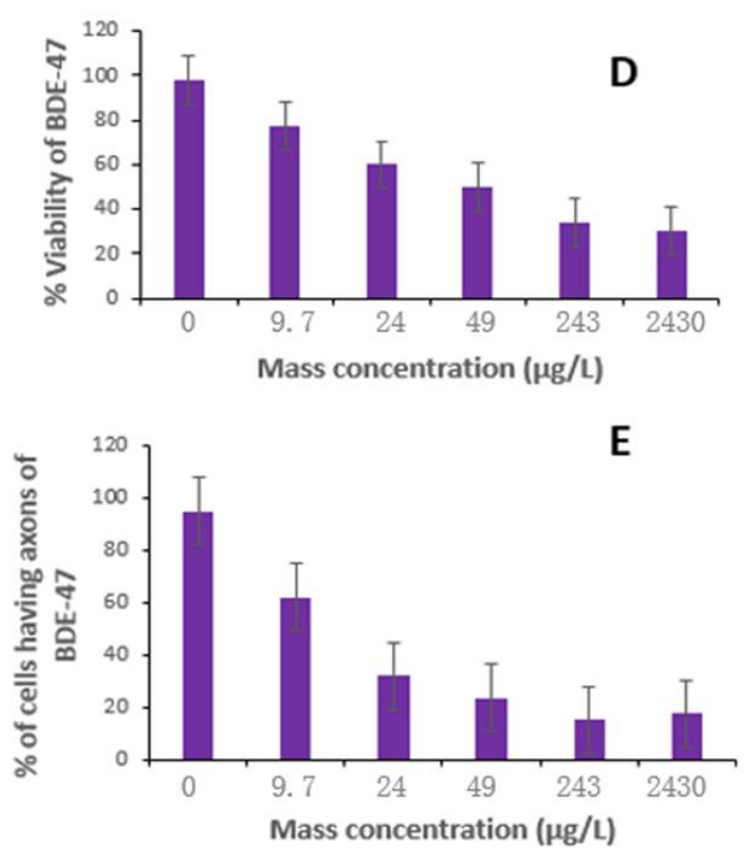

$\mathbf{F}$

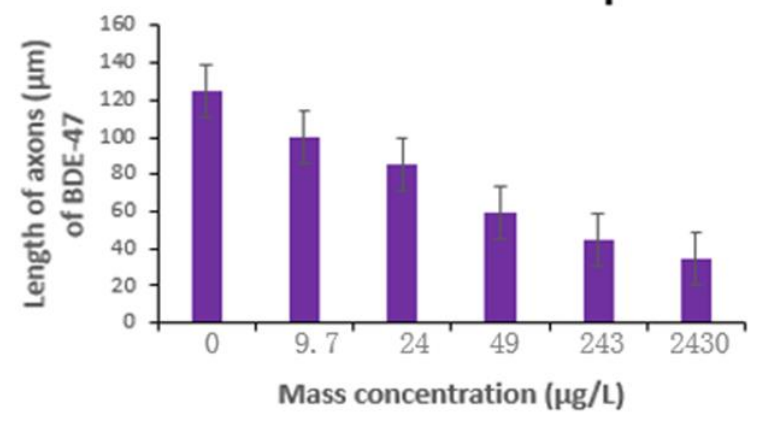

Fig. 2: PC12 cell growth and differentiation affected by PBDEs under long term exposure condition (Condition I). (A-C) Cells exposed to BDE-209; (D-E) Cells exposed to BDE-47. (A) and (D) Viability. (B) and (E) Fraction of differentiated cells. (C) and (F) Length of axons.

Table 1: PC12 cell growth and differentiation affected by PBDEs under long term exposure condition (Condition I).

\begin{tabular}{lcc}
\hline & BDE-209 $(\boldsymbol{\mu g} / \mathbf{L})$ & BDE-47 $(\boldsymbol{\mu g} / \mathbf{L})$ \\
\hline $\mathbf{5 0 \%}$ Cell viability & 500 & 50 \\
\hline $\mathbf{5 0 \%}$ Cells having axons & 50 & 15 \\
\hline $\begin{array}{l}\text { Axon growing to 50\% of norm } \\
\text { length }\end{array}$ & 100 & 50 \\
\hline
\end{tabular}

3.2. Acute exposure to high concentration PBDEs (Condition II). For comparison to the low dose exposure studies, we also mimicked the acute exposure conditions that living species may encounter. The cells were grown under normal conditions. Before differentiation, the cells were exposed to cell culture media containing a high total PBDE concentration: BDE-47 (50 $\mu \mathrm{g} / \mathrm{L}$ to $10 \mathrm{mg} / \mathrm{L}$ ) or BDE-209 
$(100 \mu \mathrm{g} / \mathrm{L}$ to $20 \mathrm{mg} / \mathrm{L})$, for 12 hours. The cells were then washed off PBDEs and treated with NGF for differentiation.

A complete viability and cell differentiation analysis for both PBDEs is reported in Figure 3. After acute exposure, the LC50 concentration was estimated to be $\sim 5 \mathrm{mg} / \mathrm{L}$ for BDE-209 and $\sim 1 \mathrm{mg} / \mathrm{L}$ for BDE-47, respectively. However, for the surviving cells, the cell differentiation and growth were significantly interfered. The fraction of cells having axons dropped to $27 \pm 3 \%$ and $10 \pm 4 \%(n \geq 5, n$ is the number of images of multiple cells) for $0.1 \mathrm{mg} / \mathrm{L}$ BDE-209 and $0.05 \mathrm{mg} / \mathrm{LBDE}-47$, respectively. Compared to the length of axons in the control cells $(120 \pm 25 \mu \mathrm{m})$, the length of PBDEtreated cells dropped to $65 \pm 20 \mu \mathrm{m}$ and $30 \pm 5 \mu \mathrm{m}$ for BDE-209 and BDE-47, respectively. These studies showed that the cell differentiation and growth of PC12 cells are very sensitive to high concentration PBDE shocks, and BDE-47 was more toxic than BDE-209.
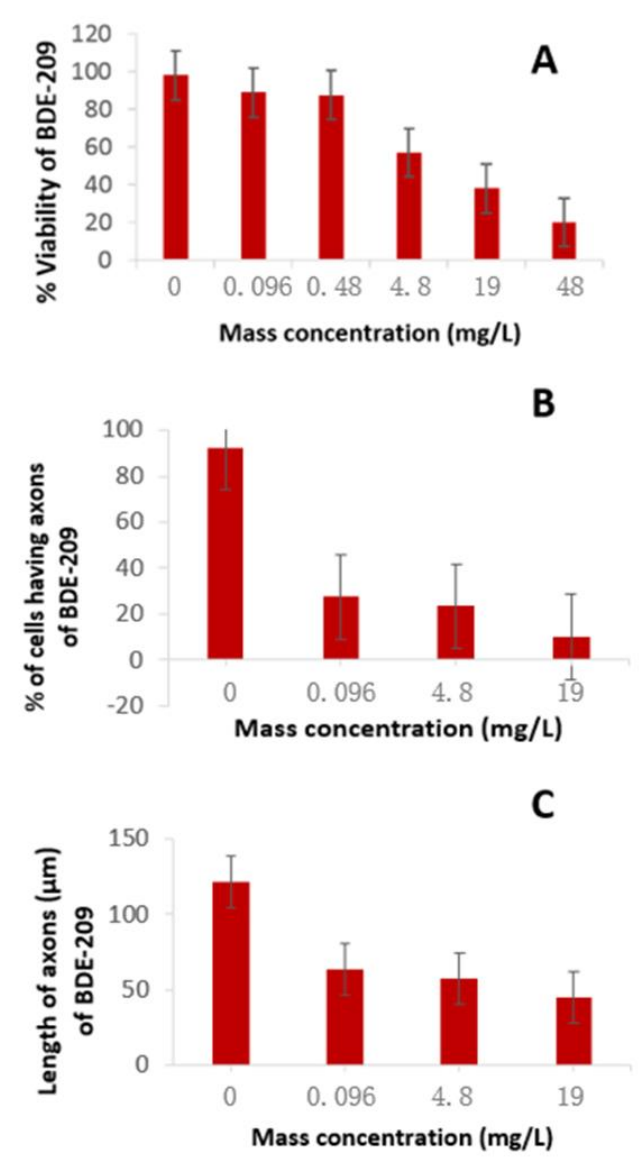
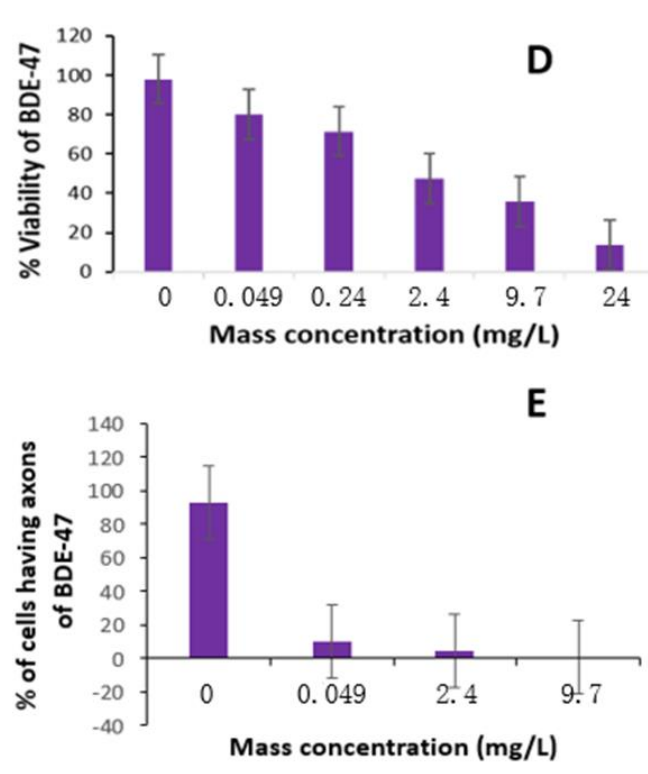

$\mathbf{F}$

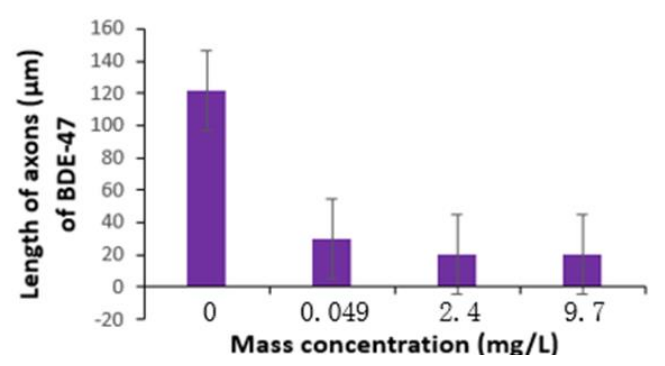

Fig. 3: PC12 cell growth and differentiation affected by PBDEs under acute exposure condition (Condition II). (A-C) Cells exposed to BDE-209; (D-E) Cells exposed to BDE-47. (A) and (D) Viability. (B) and (E) Fraction of differentiated cells. (C) and (F) Length of axons.

\subsection{Calcium release upon exposure to PBDEs}

As discussed earlier, brominated flame retardants may affect several neurotoxicity pathways in animal models but in the cell model, perturbation of calcium homeostasis and signaling may be the most probable mechanism [22, 34, 35]. In general, calcium homeostasis and signaling control a number of cellular processes starting from the genetic level to cell growth, differentiation, and 
apoptosis. In neural cells, changes in intracellular calcium levels affect various stages of neuronal development and processes including neurotransmitter uptake and release [36]. Environmentally regulated, high frequency $\mathrm{Ca}^{++}$transients have been documented to be responsible for growth-cone stalling and axon retraction [37]. Thus, undifferentiated PC12 cells and short axon length observed in PBDE treated cells in Figure 1 may be a result of PBDE-induced changes in intracellular calcium levels and perturbed calcium signaling pathways.

To confirm that calcium signaling was involved in PBDE-disrupted cell differentiation and axon growth, we measured calcium release of live, undifferentiated PC12 cells exposed to different concentrations of BDE-47 and BDE-209 using Fluro- 8 calcium detection assays. When Fluro- 8 enters the cell, the esterase enzyme in live cells cleaves the lipophilic blocking groups in fluo- 8 , resulting in negatively charged fluorescent dye Fluo- 8 . In the presence of stimulants, calcium sensing receptors are activated, releasing calcium ions from intracellular calcium stores into the cytoplasm. The transiently released free calcium ions bind to Fluo- $8^{-}$dye, resulting in significant increase in fluorescence.

The representative epifluorescent images of live, undifferentiated PC12 cells collected shortly (1 min) after BDE-47 or BDE-209 exposures are shown in Figure 4. Compared to untreated cells (Figure 4A), cells exposed to PBDE were significantly brighter, with the cell brightness increasing with the increase in PBDE concentration. Thus PBDE induced intracellular $\mathrm{Ca}^{++}$release and perturbed normal $\mathrm{Ca}^{++}$balance in the PC12 cells. Figure 4E shows the concentration-dependent analysis of average cell brightness. At low PBDE concentrations, a linear relationship was identified. Under current experimental settings, the lowest detectable $\mathrm{Ca}^{++}$signal, according to the background plus three times of the standard deviation rule, was generated by the exposure of $250 \mu \mathrm{g} / \mathrm{L}$ PBDE- 47 . The correlation between PBDE concentration-dependent calcium release and the perturbation of axon growth suggests that disrupted calcium signaling is involved in the perturbed PC12 differentiation. As reported by AlMousa and Michelangeli [38]. PBDE-induced calcium release is most likely due to the perturbation of active of $\mathrm{Ca}^{++}$receptors. Figure $4 \mathrm{E}$ also showed that, at the same concentration, BDE-47 exposure triggered more calcium release than exposure to BDE-209. This was consistent with the observation that BDE-47 had more impact on cell differentiation and survival than BDE-209.

\subsection{Perturbation of cytoskeleton protein F-actin}

To study the possible perturbation of brominated flame retardants on actin cytoskeleton as a factor directly related to the axon growth, treated cells were fixed and stained with phalloidin-FITC. Phalloidin is a protein that specifically binds to F-actins with high affinity $\left(\mathrm{K}_{A} / \mathrm{K}_{\mathrm{D}} \sim 40 \mu \mathrm{M}^{-1}\right)$ [39].

The fluorescent images of differentiated PC12 cells grown in the presence of BDE-209 and BDE-47 under Condition I are shown in Figure 5.

Since phalloidin specifically binds to F-actin, the brightness in the image correlates with the F-actin distribution. Under long term exposure to low concentrations of PBDEs, the actin distribution did not have obvious observable changes. However, the cells became brighter continuously as the PBDE concentration increased from 0 to $500 \mu \mathrm{g} / \mathrm{L}$ for BDE-209, or 0 to $250 \mu \mathrm{g} / \mathrm{L}$ for BDE-47. The quantitative fluorescence intensity (average over twenty cells) as a function of PBDE concentration is shown in Figure 6.

Both BDE-209 and BDE-47 treated cells showed higher fluorescence intensity as PBDE concentration increased. Further increasing PBDE concentration above $500 \mu \mathrm{g} / \mathrm{L}$ for BDE-209 or 250 
$\mu \mathrm{g} / \mathrm{L}$ for BDE-47 showed a decrease of the abnormally high fluorescence level, possibly indicating the abnormal actin expressing activity was hampered.
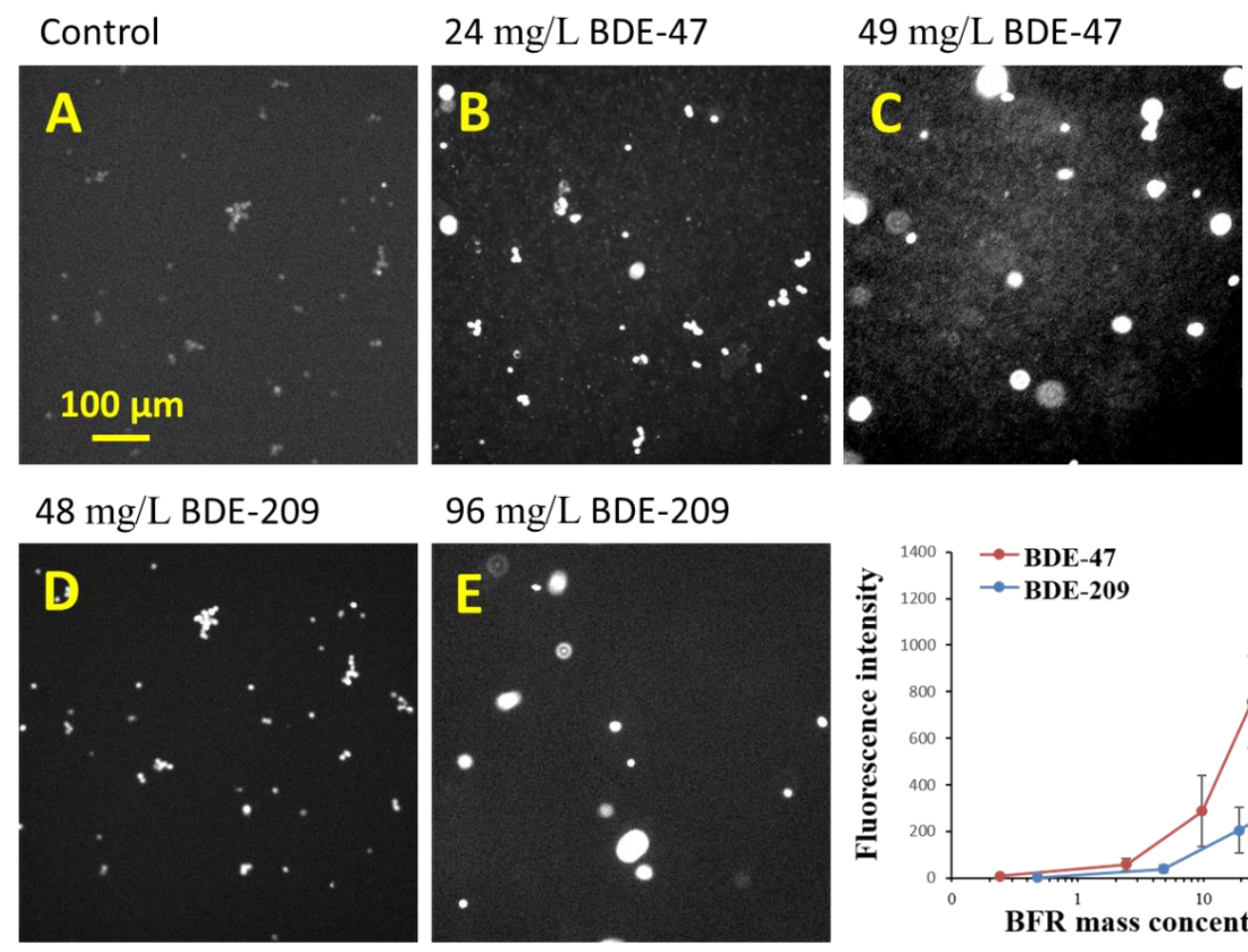

$96 \mathrm{mg} / \mathrm{L}$ BDE-209
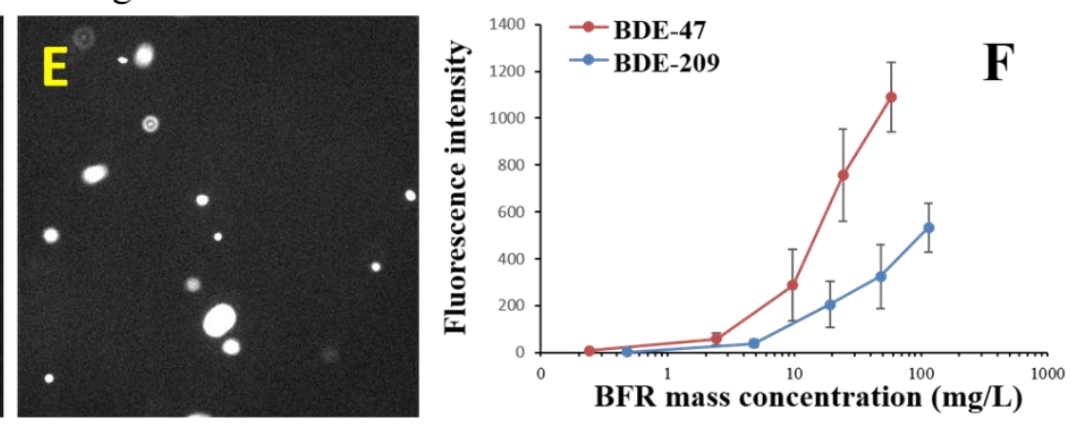

Fig. 4: Calcium release as a function of PBDE concentration. Representative epifluorescent images of (A) untreated live PC12 cells; (B) and (C) PC12 cells treated with different concentrations of BDE47; and (D) and (E) BDE-209. (F) Fluorescence intensity as a function of PBDE concentration. Exposure condition II. Scale bar: $100 \mu \mathrm{m}$.

No increased fluorescence intensity was evident in cells treated with high concentrations of PBDEs under Condition II. However, the F-actin morphology was significantly different in treated cells than the control cells, showing bright patches localized at the cell periphery after exposure to both types of PBDE (Figure 7). In addition, the cells treated with high concentrations of PBDEs showed shorter axons, with hairy fibers at the periphery of the cells.

Prior reports using other types of cells document increases in actin concentration after exposure to PBDEs. For example, from the biochemical analysis of microsomal pellets sedimented from homogenized mussel tissues exposed to $\sim 10 \mathrm{nM}$ (equivalent to $5 \mu \mathrm{g} / \mathrm{L}$ ) concentration of BDE-47, Jonsson et al. found $\sim$ two fold increase in actin [40]. Similarly, Alm et al. reported that actin proteins in microsomal and cytosol pellets of developing cerebral cortex tissue of mouse treated with BDE-99 increased by a factor of $\sim 1.5$ [41]. These findings showed that PBDEs increased the total actin expression, which may explain the observed increased amount of F-actins. Our studies showed there was a correlation between the over expression of actin and the perturbed PC12 cell differentiation and suppressed axon growth. However, it was unclear how PBDEs affected actin expression and whether actin overexpression was the direct cause of the perturbed cell differentiation and suppressed axon growth. 
At high PBDE concentrations, the over-expression of actin was not observed, possibly due to the lower activity of the cells in a toxic environment. However, the phalloidin-FITC-tagged F-actin showed different localization in live cells. This may be caused by other negative effects of short term exposure to the high PBDE concentrations. For example, it has been reported that few hours after exposure of human neuroblastoma cells to $\sim 1 \mu \mathrm{M}(\sim 0.5 \mathrm{mg} / \mathrm{L})$ BDE-47, reactive oxygen species (ROS) were produced in significant amount [42]. Thus, it was very likely that high concentration of BDE-47 or BDE-209 can cause ROS-induced F-actin re-distribution [43]. As the actin organization is essential in axon growth and extension, the disruption of spatial distribution of actin may further disrupt the axon growth under high PBDE concentrations.
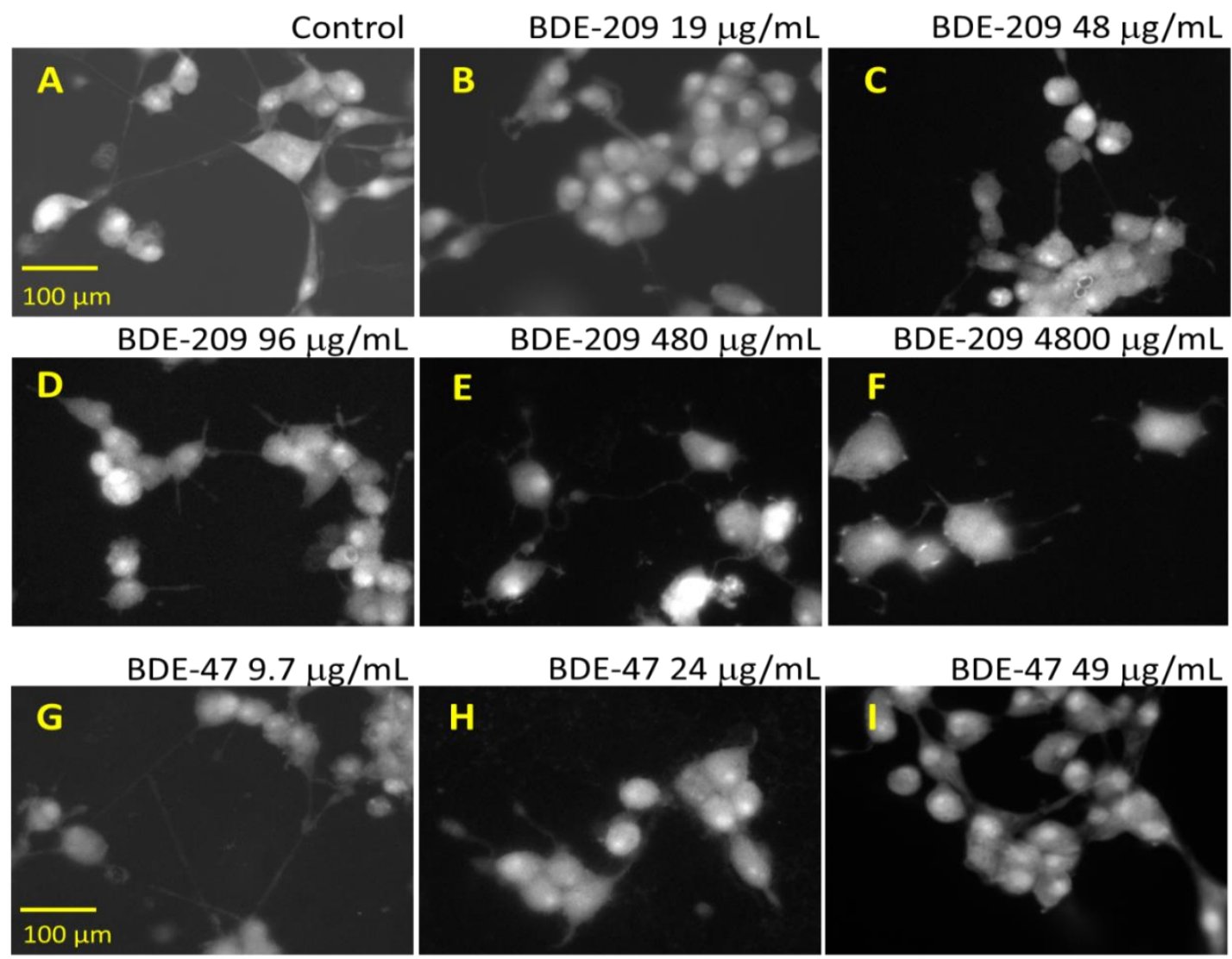

BDE-47 $243 \mu \mathrm{g} / \mathrm{mL}$
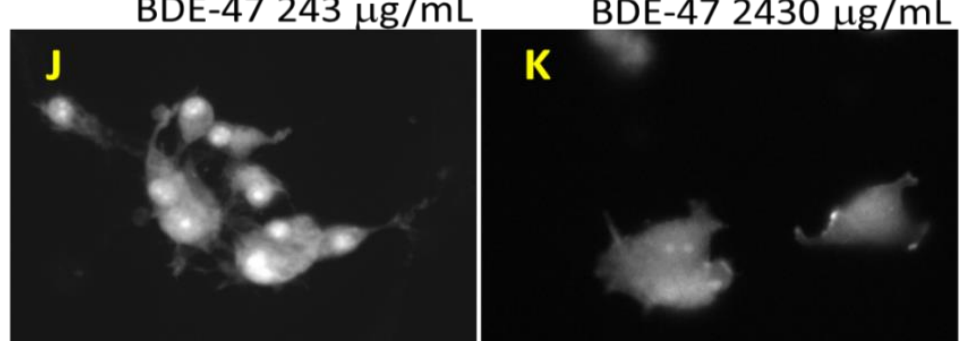

Fig. 5: Epifluorescent images of differentiated, phalloidin-FITC stained PC12 cells treated with different concentrations of (A-F) BDE-209 and (G-K) BDE-47. Exposure condition I - long term exposure. Scale bar: $100 \mu \mathrm{m}$. 

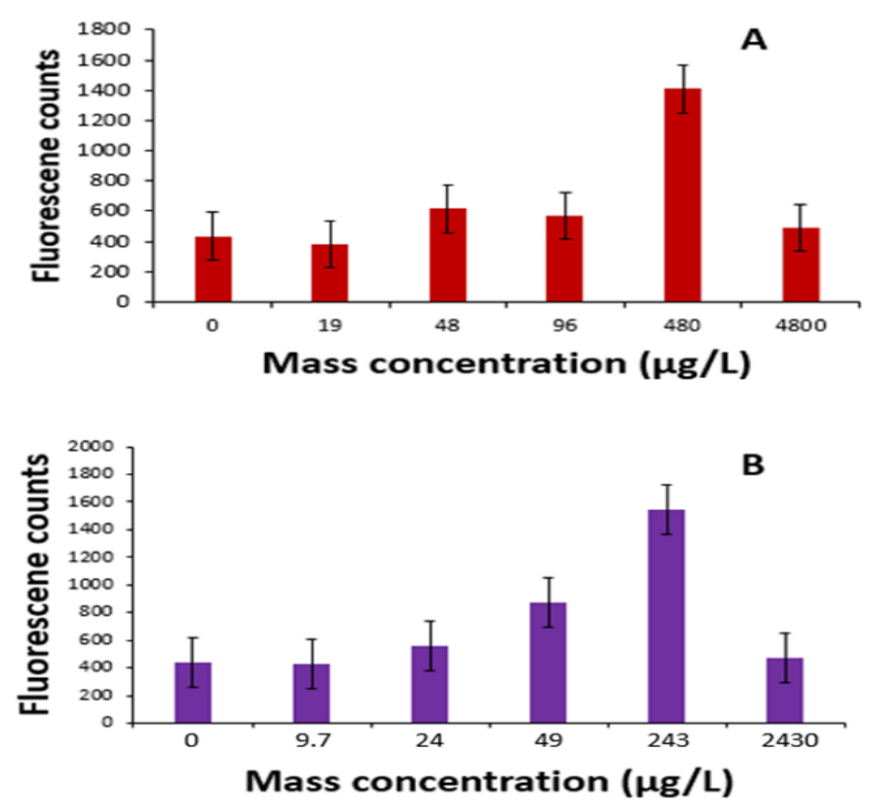

Fig. 6: Fluorescence intensity analysis of phalloidin-FITC stained PC12 cells treated with different concentrations of (A) BDE-209 and (B) BDE-47. Exposure condition I.

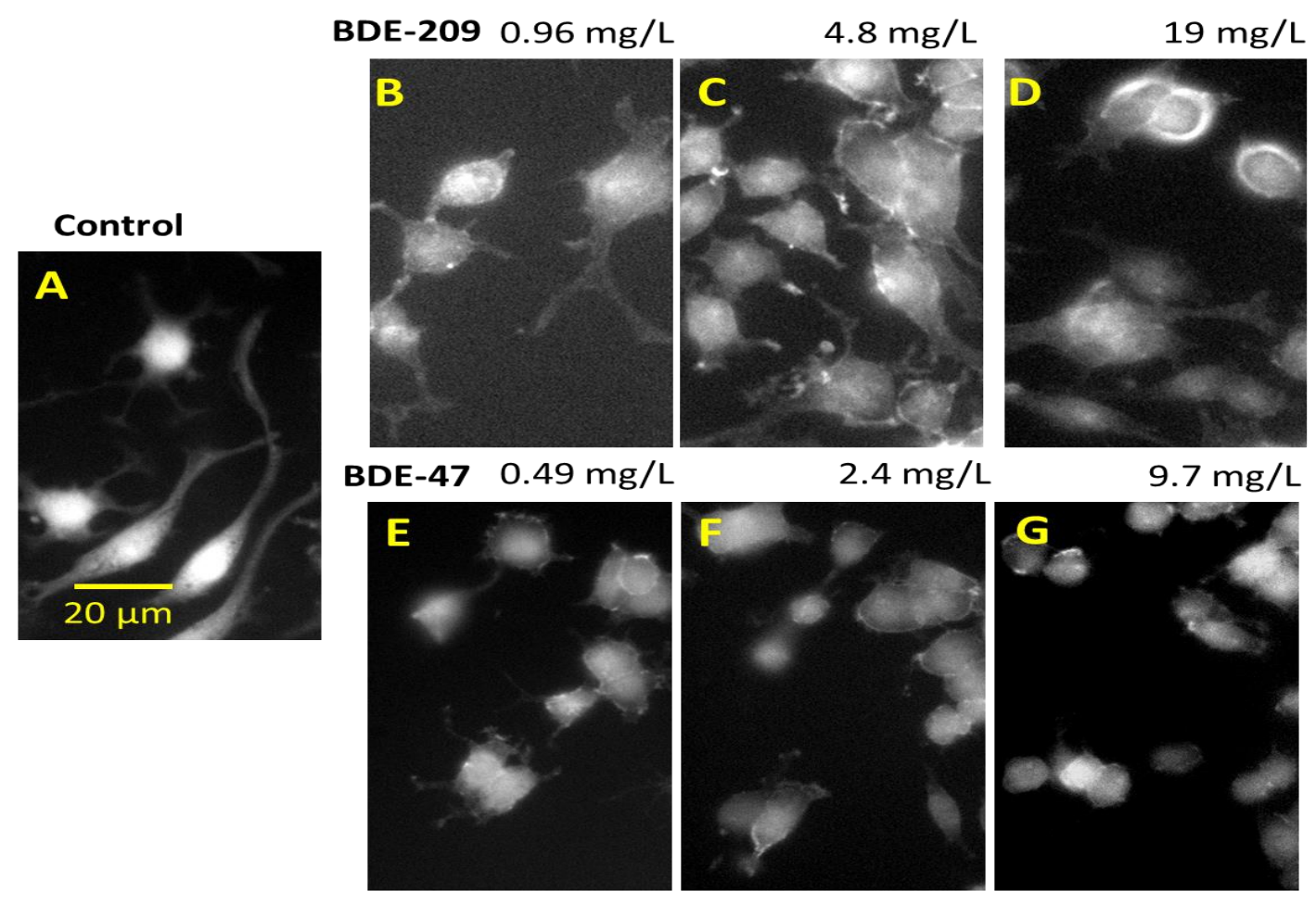

Fig. 7: Epifluorescent images of differentiated, phalloidin-FITC stained PC12 cells treated with different concentrations of (A-D) BDE-209 and (E-G) BDE-47. Exposure condition II - acute exposure. Scale bar: $20 \mu \mathrm{m}$. 


\section{Conclusion}

In summary, even at low concentrations (microgram per liter) of BDE-47 and BDE-209, neurotoxic effects were observed for PC12 neurons. Cells treated with these brominated flame retardants showed lower viability. Both the fraction of differentiated cells and the axon growth length decreased. PBDEs perturbed intracellular calcium release in a concentration-dependent manner, indicating intracellular $\mathrm{Ca}^{++}$homeostasis and signaling was involved in the neurotoxicity. Interestingly, depending on PBDE concentration and exposure conditions, cytoskeleton F-actin expression or distribution were perturbed. Long term exposure to low PBDE concentrations $(<500 \mu \mathrm{g} / \mathrm{L})$ showed increased F-actin content in PC12 cells. Under acute exposure to high concentrations ( $>0.5 \mathrm{mg} / \mathrm{L}$ ) of PBDEs, increased F-actin content was not observed but F-actin showed localized distribution at cell periphery. These indicated that PBDEs at may interrupt the cell growth and differentiation through different pathways, depending on toxicant concentration and duration of exposure. The potential neurotoxic impact of extended exposure to low concentrations of PBDEs, particularly for infants and other developing animals is a major concern.

\section{Acknowledgments}

This work is supported by a grant from the Research Innovation Seed Fund at North Carolina State University and funds from the Lampe Endowed Professorship in Biomedical Engineering (FSL).

\section{References}

[1] K. Hooper, and T. A. McDonald, The PBDEs: An emerging environmental challenge and another reason for breast-milk monitoring programs, Environmental Health Perspectives 108 (2000) 387.

[2] P. Guerra, M. Alaee, B. Jimenez, G. Pacepavicius, C. Marvin, G. MacInnis, E. Eljarrat, D. Barcelo, L. Champoux and K. Fernie. Emerging and historical brominated flame retardants in peregrine falcon (Falco peregrinus) eggs from Canada and Spain, Environment International 40 (2012) 179.

[3] S. N. Zhou, A. Buchar, S. Siddique, L. Takser, N. Abdelouahab, and J. P. Zhu, Measurements of Selected Brominated Flame Retardants in Nursing Women: Implications for Human Exposure, Environmental Science \& Technology 48 (2014) 8873.

[4] A. Schecter, M. Pavuk, O. Papke, J. J. Ryan, L. Birnbaum, and R. Rosen, Polybrominated diphenyl ethers (PBDEs) in US mothers' milk, Environmental Health Perspectives 111 (2003) 1723.

[5] K. G. Harley, A. R. Marks, J. Chevrier, A. Bradman, A. Sjodin and B. Eskenazi, PBDE Concentrations in Women's Serum and Fecundability, Environmental Health Perspectives 118 (2010) 699.

[6] M. L. Feo, M. S. Gross, B. P. McGarrigle, E. Eljarrat, D. Barcelo, D. S. Aga, and J. R. Olson, Biotransformation of BDE-47 to Potentially Toxic Metabolites Is Predominantly Mediated by Human CYP2B6, Environmental Health Perspectives 121 (2013) 440.

[7] M. Athanasiadou, S. N. Cuadra, S. N. G. Marsh, A. Bergman, and K. Jakobsson, Polybrominated diphenyl ethers (PBDEs) and bioaccumulative hydroxylated PBDE metabolites in young humans from Managua, Nicaragua, Environmental Health Perspectives 116 (2008) 400.

[8] J. E. Goodman, Neurodevelopmental effects of decabromodiphenyl ether (BDE-209) and implications for the Reference Dose, Regulatory Toxicology and Pharmacology 54 (2009) 91.

[9] M. Banasik, Prenatal PBDEs and Neurodevelopment: Animal Studies and Human Health Assessment, Environmental Health Perspectives 118 (2010) A468.

[10] J. M. Donohue, H. Galal-Gorchev, and M. Manibusan, Toxicoogical Review of 2,2',4,4'-tetrabromo Diphenyl ether (BDE-47),U.S. Environmental Protection Agency (2008) EPA/635/R-07/005F. 
[11] UNEP, Persistent Organic Pollutants Review Committee of the Stockholm Convention. Commercial Pentabromodiphenyl Ether: Risk Management Evaluation. 1-19 Geneva (2007) Swizerland: United Nations Environment Programme.

[12] UNEP, Stockholm convention:Listing of hexabromodiphenyl ether,heptabromodiphenyl ether, Part IV of Annex A (2009) decision SC-4/14, Geneva, Swizerland.

[13] E. Mariussen, and F. Fonnum, The effect of brominated flame retardants on neurotransmitter uptake into rat brain synaptosomes and vesicles, Neurochemistry International 43 (2003) 533.

[14] O. A. Ogunbayo, P. F. Lai, T. J. Connolly, and F. Michelangeli, Tetrabromobisphenol A (TBBPA), induces cell death in TM4 Sertoli cells by modulating $\mathrm{Ca}(2+)$ transport proteins and causing dysregulation of $\mathrm{Ca}(2+)$ homeostasis, Toxicology in Vitro 22 (2008) 943.

[15] X. J. Chen, C. J. Huang, X. C. Wang, J. F. Chen, C. L. Bai, Y. H. Chen, X. P. Chen, Q. X. Dong, D. R. Yang, BDE-47 disrupts axonal growth and motor behavior in developing zebrafish, Aquatic Toxicology 120 (2012) 35.

[16] X. M. Ren, and L. H. Guo, Molecular toxicology of polybrominated diphenyl ethers: nuclear hormone receptor mediated pathways, Environmental Science-Processes \& Impacts 15 (2013) 702.

[17] X. M. Ren, L. H. Guo, Y. Gao, B. T. Zhang, B. Wan, Hydroxylated polybrominated diphenyl ethers exhibit different activities on thyroid hormone receptors depending on their degree of bromination, Toxicology and Applied Pharmacology 268 (2013)256.

[18] J. Legler, A. Brouwer, Are brominated flame retardants endocrine disruptors? Environment International 29 (2003) 879.

[19] H. S. Hendriks, M. Meijer, M. Muilwijk, M. van den Berg, R. H. S. Westerink, A comparison of the in vitro cyto- and neurotoxicity of brominated and halogen-free flame retardants: prioritization in search for safe(r) alternatives, Archives of Toxicology 88 (2014) 857.

[20] R. H. S. Westerink, Modulation of cell viability, oxidative stress, calcium homeostasis, and voltage- and ligand-gated ion channels as common mechanisms of action of (mixtures of) non-dioxin-like polychlorinated biphenyls and polybrominated diphenyl ethers, Environmental Science and Pollution Research 21 (2014)6373-6383.

[21] M. M. L.Dingemans, A. de Groot, R. van Kleef, A. Bergman, M. van den Berg, H. P. M. Vijverberg, R. H. S. Westerink, R. H. S., Hydroxylation increases the neurotoxic potential of BDE-47 to affect exocytosis and calcium homeostasis in PC12 cells, Environmental Health Perspectives 116 (2008) 637.

[22] M. M. L.Dingemans, H. J. Heusinkveld, A. Bergman, M. van den Berg, and R. H. S.Westerink, Bromination Pattern of Hydroxylated Metabolites of BDE-47 Affects Their Potency to Release Calcium from Intracellular Stores in PC12 Cells, Environmental Health Perspectives 118 (2010a) 519.

[23] M. M. L. Dingemans, G. M. J. Ramakers, F. Gardoni, R. van Kleef, A. Bergman, M. Di Luca, M. van den Berg, R. H. S. Westerink, H. P. M.Wijverberg, Neonatal exposure to brominated flame retardant BDE-47 reduces long-term potentiation and postsynaptic protein levels in mouse hippocampus, Environmental Health Perspectives 115 (2007) 865.

[24] X. J. Chen, C. J. Huang, X. C. Wang, J. F. Chen, C. L. Bai, Y. H. Chen, X. P. Chen, Q. X. Dong, and D. R. Yang, BDE-47 disrupts axonal growth and motor behavior in developing zebrafish, Aquatic Toxicology 120 (2012) 35.

[25] T. Li, W. B. Wang, Y. W. Pan, L. H. Xu, and Z. G. Xia, A Hydroxylated Metabolite of Flame-Retardant PBDE-47 Decreases the Survival, Proliferation, and Neuronal Differentiation of Primary Cultured Adult Neural Stem Cells and Interferes with Signaling of ERK5 MAP Kinase and Neurotrophin 3, Toxicological Sciences 134 (2013)113.

[26] W. K. Chan, and K. M. Chan, Disruption of the hypothalamic-pituitary-thyroid axis in zebrafish embryolarvae following waterborne exposure to BDE-47, TBBPA and BPA, Aquatic Toxicology 108 (2012) 106. 
[27] T. Hamers, J. H. Kamstra, E. Sonneveld, A. J. Murk, M. H. A. Kester, P. L. Andersson, J. Legler, and A. Brouwer, In vitro profiling of the endocrine-disrupting potency of brominated flame retardants, Toxicological Sciences 92 (2006)157.

[28] W. R. Mundy, T. M. Freudenrich, K. M. Crofton, M. J. DeVito, M. J., Accumulation of PBDE-47 in primary cultures of rat neocortical cells, Toxicological Sciences 82 (2004)164.

[29] C. Dillon, and Y. Goda, The actin cytoskeleton: Integrating form and function at the synapse, Annual Review of Neuroscience 28 (2005) 25.

[30] E. W. Dent, and F. B. Gertler, Cytoskeletal dynamics and transport in growth cone motility and axon guidance, Neuron 40 (2003) 209.

[31] L. A. Cingolani, Y. Goda, Actin in action: the interplay between the actin cytoskeleton and synaptic efficacy, Nature Reviews Neuroscience 9 (2008) 344.

[32] L. C. Kapitein, and C. C Hoogenraad, Which way to go? Cytoskeletal organization and polarized transport in neurons, Molecular and Cellular Neuroscience 46 (2011)9.

[33] S. P. C. Huang, G. Giordano, and L. G. Costa, Comparative Cytotoxicity and Intracellular Accumulation of Five Polybrominated Diphenyl Ether Congeners in Mouse Cerebellar Granule Neurons, Toxicological Sciences 114 (2010)124.

[34] T. Hassenklöver, and U. Bickmeyer, The marine secondary metabolites 2,4-dibromophenol and 2,4,6tribromophenol differentially modulate voltage dependent ion currents in neuroendocrine (PC12) cells, Aquatic Toxicology 79 (2006) 384.

[35] M. M. L. Dingemans, M. van den Berg, A. Bergman, A. and R. H. S. Westerink, Calcium-Related Processes Involved in the Inhibition of Depolarization-Evoked Calcium Increase by Hydroxylated PBDEs in PC12 Cells, Toxicological Sciences 114 (2010b)302.

[36] M. J. Berridge, M. D. Bootman, P. Lipp, Calcium - a life and death signal, Nature 395 (1998) 645.

[37] T. M. Gomez, and N. C. Spitzer, In vivo regulation of axon extension and pathfinding by growth-cone calcium transients, Nature 397 (1999) 350.

[38] F. Al-Mousa,and F. Michelangeli, The sarcoplasmic-endoplasmic reticulum $\mathrm{Ca}^{2+}$-ATPase (SERCA) is the likely molecular target for the acute toxicity of the brominated flame retardant hexabromocyclododecane (HBCD), Chemico-Biological Interactions 207 (2014) 1.

[39] E. Wulf, A. Deboben, F. A. Bautz, H. Faulstich, and T. Wieland, Fluorescent phallotoxin, a tool for the visualization of cellular actin, Proceedings of the National Academy of Sciences of the United States of America 76 (1979) 4498.

[40] H. Jonsson, D. Schiedek, A. Goksøyr, and B. E. Grøsvik, Expression of cytoskeletal proteins, crossreacting with anti-CYP1A, in Mytilus sp. exposed to organic contaminants Aquatic Toxicology 78 (2006) Supplement(0) S42-S48.

[41] H. Alm, K. Kultima, B, Scholz, A. Nilsson, P. E. Andrén, Å, Fex-Svenningsen, L. Dencker, and M. Stigson, Exposure to brominated flame retardant PBDE-99 affects cytoskeletal protein expression in the neonatal mouse cerebral cortex, NeuroToxicology 29 (2008) 628.

[42] S. Tagliaferri, A. Caglieri, M. Goldoni, S. Pinelli, R. Alinnovi, D. Poli, C. Pellacani, G. Giordano, A. Mutti, and L. G. Costa, Low concentrations of the brominated flame retardants BDE-47 and BDE-99 induce synergistic oxidative stress-mediated neurotoxicity in human neuroblastoma cells, Toxicology in Vitro 24 (2010)116.

[43] K. A. Wilkins, J. Bancroft, M. Bosch, J. Ings, N. Smirnoff, and V. E. Franklin-Tong, Reactive Oxygen Species and Nitric Oxide Mediate Actin Reorganization and Programmed Cell Death in the SelfIncompatibility Response of Papaver, Plant Physiology 156 (2011)404. 